\title{
Targeted gene expression in the transgenic Aedes aegypti using the binary Gal4-UAS system
}

\author{
Vladimir A. Kokoza and Alexander S. Raikhel ${ }^{\star}$ \\ Department of Entomology and Institute for Integrative Genome Biology, University of California \\ Riverside, Riverside CA 92521
}

\begin{abstract}
In this study, we report the establishment of the binary Gal4/UAS system for the yellow fever mosquito Aedes aegypti. We utilized the 1.8-kb 5' upstream region of the vitellogenin gene $(V g)$ to genetically engineer mosquito lines with the $V g$-Gal4 activator and established UAS-EGFP responder transgenic mosquito lines to evaluate the binary Gal4/UAS system. The results show that the $V g$-Gal4 driver leads to a high level of tissue-, stage- and sex-specific expression of the $E G F P$ reporter in the fat body of $V g-G a l 4 / U A S-E G F P$ hybrids after blood-meal activation. In addition, the applicability of this system to study hormonal regulation of gene expression was demonstrated in in vitro organ culture experiments in which the EGFP reporter was highly activated in isolated fat bodies of previtellogenic $\mathrm{Vg}$-Gal4/UAS-EGFP females incubated in the presence of 20-hydroxyecdysone (20E). Hence, this study has opened the door for further refinement of genetic tools in mosquitoes.
\end{abstract}

\section{Keywords}

genetic transformation; vitellogenin promoter; piggyBac transposable element

\section{Introduction}

\begin{abstract}
Mosquitoes transmit numerous pathogens of devastating human diseases. Advances in mosquito molecular biology, genetics and genomics have been stirred by demands to develop novel and perfect already-existing approaches for mosquito control. Genomes have been sequenced for three mosquitoes: Anopheles gambiae, Aedes aegypti and Culex quinquefasciatus, vectoring malaria, Dengue and Yellow fevers, and West Nile virus, respectively (Arensburger et al., 2010; Holt et al., 2002; Nene et al., 2007). Introduction of RNA interference reverse genetics (RNAi), microarray and RNA-sequence technologies has empowered vector research (Blandin et al., 2002; Dimopoulos et al., 2002, Bonizonni et al., 2011; Niera-Ovieda et al., 2011), and development of genetic transformation in mosquitoes has played a significant role in enriching a genetic toolbox available for mosquito research (Catteruccia et al., 2000; Coates et al., 1998; Jasinskiene et al., 1998; Kokoza et al., 2000; Kokoza et al., 2001a; Kim et al., 2004). During the last decade, great progress has been achieved in the development of these novel strategies for potential mosquito and pathogen
\end{abstract}

(C) 2011 Elsevier Ltd. All rights reserved.
*To whom correspondence should be addressed: alexander.raikhel@ucr.edu.

Publisher's Disclaimer: This is a PDF file of an unedited manuscript that has been accepted for publication. As a service to our customers we are providing this early version of the manuscript. The manuscript will undergo copyediting, typesetting, and review of the resulting proof before it is published in its final citable form. Please note that during the production process errors may be discovered which could affect the content, and all legal disclaimers that apply to the journal pertain. 
control (James, 2005; Terenius et al., 2008). A transgenic approach was used in studies of mosquito immunity (Antonova et al., 2009; Bian et al., 2005; Shin et al., 2003; Shin et al. 2006; Cheon et al., 2006), and transgenesis has been instrumental in demonstrating a proofof-principal concept of creating a vector with elevated resistance to a malaria pathogen (Ito et al., 2002; Kim et al., 2004). Using RNA interference techniques, there has been success in engineering partial Dengue virus resistance in Ae. aegypti (Franz et al., 2006; Mathur et al., 2010). Kokoza et al. (2010) showed that co-overexpression of two effector molecules with anti-pathogen action in the same transgenic mosquito results in a total refractory phenotype. Transgenesis has recently been used to engineer a repressive, female-specific, flightless phenotype in Ae. aegypti mosquitoes; this holds promise for control of mosquito populations (Fu et al., 2010). Transgenic manipulation of regulatory pathways opens the possibility of decreasing the life span of mosquitoes (Corby-Harris et al., 2010).

Despite this impressive gain in knowledge of molecular genetics of mosquitoes, there is an urgent need to develop and refine methods of genetic engineering in these disease vectors. It is of particular importance for evaluating genes that have detrimental effects on development, reproduction, nutritional and metabolic processes, and other aspects of mosquito biology.

One powerful genetic approach is the conditional targeting of gene expression using the binary Gal4/UAS system (Ornitz et al., 1991, Brand and Perrimon, 1993). This system has been essential for genetic research in Drosophila (Brand and Perrimon, 1993, Duffy, 2002; McGuire et al., 2004), as well as several other model organisms, such as mice (Ornitz et al., 1991; Mallo, 2006), zebra fish (Scheer and Campos-Ortega, 1999; Baier and Scott, 2009), Xenopus (Hartley et al., 2002) and Arabidopsis (Guyer et al., 1998). Among non-

Drosophilid insects, establishment of the binary Gal4/UAS system has been reported for the silkworm, Bombyx mori (Imamura et al., 2003) and, recently, for the beetle Tribolium castaneum (Schinko et al., 2010). The established binary Gal4/UAS system is based on the production of two independent transgenic lines: one with the yeast Gal4 activator gene under a tissue-, cell-specific, inducible or constitutive promoter (the driver line), and another with the binding sites for Gal4 protein - the upstream activation sequence (UAS), which can control the expression of any gene of interest (the responder line). Crossing these two lines results in expression of a reporter gene in a hybrid organism in a manner that depends on a promoter used in the driver line (Brand and Perrimon, 1993). The binary Gal4/UAS has been essential for deciphering numerous gene functions (Duffy, 2002; McGuire et al., 2004; Mallo, 2006; Baier and Scott, 2009). The major advantage of this system is that, without an activator, no expression of the gene of interest takes place. This allows overexpression of genes with potentially harmful effects on development, behavior and fertility. Importantly, with the Gal4 binary system, it is possible to study a phenotypic effect of dominant lethal genes, producing conditional lethality in specific tissue and at a specific stage. Introduction of this technology along with characterization and cloning of an ever-increasing list of genes with specific stage, sex, tissue or cell patterns of expression has revolutionized molecular genetics of model organisms.

In this study, we report the establishment of the binary Gal4/UAS system for the yellow fever mosquito Ae. aegypti. This represents a significant step in further refinement of genetic tools in mosquitoes.

\section{Experimental Procedures}

\subsection{Mosquito rearing}

The Ae. aegypti wild-type UGAL/Rockefeller strain and transgenic lines (the driver VgGal4 and the responder UAS-EGFP) were reared at $27^{\circ} \mathrm{C}$ and $80 \%$ humidity, as described 
previously (Roy et al., 2007). Blood feeding of adult mosquitoes (4- to 5-day-old females) was performed using White Leghorn chickens.

\subsection{DNA constructs}

The germ-line transformation vectors carrying the $V g$-Gal4 driver and $U A S$-EGFP responder (Fig.1) were constructed as described below. The Vg-Gal4 driver cassette was assembled in the shuttle vector pSLfa (Horn and Wimmer, 2000). The 1.8-kb BglII-Bam HI fragment of the $V g 5^{\prime}$ promoter region (Kokoza et al., 2001b) was linked with a 0.8-kb BamHI-XbaI fragment of the chimeric Gal4 activator excised from the modified pTwiggy, one of the Drosophila transformation vectors with a driver construct (Arnosti et al., 1996, Kulkarni and Arnosti, 2003). In this version of the Gal4 activator, two essential domains, the DNA-binding (amino acids, 1-93) and activation (amino acids, 753-881), were fused directly, resulting in the chimeric Gal4 $\Delta$ activator widely used in Drosophila studies as a more effective driver than the original Gal4 protein (Kulkarni and Arnosti, 2003). The resulting $\mathrm{Vg}$-Gal4 driver construct was subcloned from the pSLfa shuttle plasmid into the $\mathrm{pBac}$ [3xP3-EGFP $\mathrm{afm}$ ] transformation vector in the AscI unique cloning site. The $\mathrm{pBac}$ [3xP3-EGFP afm, $V g$-Gal4] construct has a marker EGFP gene driven by the $3 x P 3$ eyespecific promoter and was used for germ-line transformation to produce the driver transgenic line.

The UAS-EGFP responder cassette was made by linking the $0.5-\mathrm{kb}$ BamHI-BglII fragment of pUAST vector (Brand and Perrimon, 1993) with a $0.75-\mathrm{kb}$ EGFP sequence, followed by a $0.25-\mathrm{kb}$ SV40 polyadenylation signal in the pSLfa shuttle plasmid. The 5' region of this construct has five tandemly arrayed GAL4 binding sites, the upstream activation sequence $(U A S)$, followed by $H s p 70$ basal promoter with TATA box and a 68-bp leader sequence (Brand and Perrimon, 1993). The activation of this 5' upstream region by the DNA binding domain of the GAL4 protein drives the EGFP gene expression as a reporter part of the construct. The 1.5-kb UAS-EGFP responder cassette was introduced into the $\mathrm{pBac}[3 \times \mathrm{xP}-$ DsRed $a f m]$ transformation vector (Horn and Wimmer, 2000) at the unique AscI site. The resulting $\mathrm{pBac}[3 \times \mathrm{x} 3$-DsRed afm, $U A S-E G F P]$ plasmid has a marker DsRed gene driven by a $3 \mathrm{xP} 3$ eye-specific promoter and was used for mosquito germ-line transformation to produce a responder line.

\subsection{Germ-line transformation}

The germ-line transformation was performed as described previously (Kokoza et al., 2001). Briefly, the DNA of the pBac [3xP3-EGFP afm, Vg-Gal4] driver, pBac[3xP3-DsRed afm, $U A S-E G F P]$ responder, and phsp-pBac helper plasmid (Handler and Harrell, 1999) was purified using a QIAFilter kit (QIAGEN) and dissolved in $0.1 \mathrm{mM}$ phosphate buffer $(\mathrm{pH}$ $6.8), 5 \mathrm{mM} \mathrm{KCl}$. The mixture of the vector and helper DNA, at the final concentrations of $0.35 \mathrm{mg} / \mathrm{ml}$ and $0.25 \mathrm{mg} / \mathrm{ml}$, respectively, was injected into pre-blastoderm eggs of the wildtype UGAL/Rockefeller strain. Eggs for injection experiments were collected $72 \mathrm{~h}$ postblood meal (PBM). The development of Vg-Gal4 driver and UAS-EGFP responder transgenic lines was done essentially as described previously (Kokoza et. al., 2001a), based on $\mathrm{G}_{1}$ progeny selection, using the EGFP and DsRed $3 \mathrm{xP} 3$ eye-specific selectable markers (Horn et al., 2002). The hybrid line $V g$-Gal4/UAS-EGFP hybrid mosquitoes was established as previously described (Kokoza et al., 2010).

\subsection{Molecular analysis (Genomic PCR, Inverse PCR and RT-PCR)}

Genomic DNA from transgenic and wild-type mosquitoes was purified using the DNeasy tissue kit (QIAGEN). PCR was performed using $50 \mathrm{ng}$ of genomic DNA isolated from adult mosquitoes as a template. The primers used for gene amplification are listed in Table S1. 
PCR was done as follows: denaturation at $95^{\circ} \mathrm{C}$ for $2 \mathrm{~min}, 35$ cycles of $95^{\circ} \mathrm{C}$ for $30 \mathrm{~s}, 55$

${ }^{\circ} \mathrm{C}$ for $40 \mathrm{~s}$ and $68{ }^{\circ} \mathrm{C}$ for $1 \mathrm{~min}$, using Platinum Taq polymerase (Invitrogen).

Inverse PCR analysis was done using genomic DNA (5 ng) from transgenic Vg-Gal4 and UAS-EGFP mosquitoes using the TaqI and MspI endonuclease digestion to identify 5' and 3 ' junctions, respectively. The inverse PCR reaction was performed essentially as previously described (Handler et. al., 1998; Kokoza et al., 2001), with primers specific to the left and right arm of the piggyBac transposon (Table S1). The PCR products were cloned in a TA vector (Invitrogen) and the sequence from plasmid DNA of the five to seven independent clones was determined for each junction.

Total RNA from the transgenic and wild-type mosquitoes was isolated by the Trizol reagent (Invitrogen) using the manufacturer's protocol. Contaminating genomic DNA was removed from the RNA preparation by treatment with DNAse I (GIBCO BRL/Invitrogen). The cDNA was synthesized using the Omniscript Reverse transcriptase kit (Qiagen), in a 20- $\mu 1$ reaction mixture containing $1 \mu \mathrm{g}$ of the total RNA and oligo-dT primers, via incubation at $37^{\circ} \mathrm{C}$ for $1 \mathrm{~h}$. The PCR reactions were performed as previously described (Kokoza et. al., 2000, 2001a) using gene-specific primers (Table S2). To detect the transgenic transcripts, we designed a pair of primers that specifically recognized $\mathrm{Vg}$-Gal4 or UAS-EGFP mRNA. For driver construct, the 5' leader sequence of Vg mRNA was used as forward primer, and the sequence from the Gal4 protein reading frame was used as reverse. To detect the expression of the responder construct, the forward primer was designed from the 5' leader sequence of hsp70 mRNA present in the $U A S$ fragment, and the reverse primer was from the EGFP protein-coding sequence.

\subsection{Microscopy and Epifluorescence Analysis}

The expression of EGFP from the driver construct pBac[3xP3-EGFP afm, $V g$-Gal4] and expression of DsRed from the responder pBac[3xP3-DsRed afm, UAS-EGFP] in the transgenic mosquitoes were detected using a Nikon SMZ800 fluorescence microscope equipped with a GFP-B and DsRed filter set, respectively. The images were captured using a Nikon DXM 200 digital system. This system was also used for visual observation of the adult females to detect EGFP expression in the fat body of transgenic and wild-type mosquitoes after blood meal activation.

For EGFP fluorescence detection in the previtellogenic fat body of Vg-Gal/UAS-EGFP hybrids, after in vitro incubation with the hormone $20 \mathrm{E}$, the individual fat bodies were first fixed in $3.7 \%$ formaldehyde in Aedes physiological saline (APS) buffer solution for $20 \mathrm{~min}$ at room temperature. They were then washed three times for $10 \mathrm{~min}$ in APS and transferred into a DNA-staining solution containing 5 $\mu \mathrm{M}$ Hoescht 33342 (H1399, Invitrogen) in APS for $10 \mathrm{~min}$. Finally, the fat bodies were mounted in VectaShield-H1000 (Vector Laboratories) mounting media for the fluorescence, and imaging was performed under a Zeiss AxioObserver A1 microscope, using AxioVision software.

\subsection{In Vitro Fat Body Culture}

In vitro fat body culture was performed as previously described (Raikhel et.al., 1997; Roy et al., 2007). An established system contained a mixture of all amino acids $(120 \mathrm{nM} / \mu \mathrm{l})$ in the incubation medium in the presence or absence of $20 \mathrm{E}$ (Sigma) with a final concentration of $10 \mu \mathrm{M}$. Fat bodies isolated from previtellogenic females 3-5 days post-eclosion were incubated in the in vitro culture medium in the presence or absence of $20 \mathrm{E}$ for $6-8 \mathrm{~h}$ at 27 ${ }^{\circ} \mathrm{C}$ in an incubator. After incubation, the fat bodies were harvested and used to isolate RNA by means of the Trizol method, or prepared for fluorescence microscopy analysis. 


\section{Results}

\subsection{Transformation experiments and genomic analysis}

To generate the transgenic Ae. aegypti Gal4 driver line, we first constructed a transposon based on a piggyBac transposable element (Fig. 1A). This $V g$-Gal4 driver construct included a mosquito $1.8-\mathrm{kb} \mathrm{Vg}$ gene promoter region linked to the modified yeast $\mathrm{Gal} 4$ protein coding sequence containing the DNA binding domain (amino acid residues 1-93) and the activation domain (amino acid residues 753-881), followed by the SV40 polyadenylation signal. The driver construct also carried a selectable EGFP marker gene under the $3 \mathrm{xP} 3$ eye-specific promoter.

The piggyBac-based responder construct contained 5xUAS-five repeat concatamers of the consensus binding site for Gal4 with TATA box and the $h s p 70$ minimal promoter linked to the EGFP reporter gene and SV40 polyadenylation sequence. This responder transposon included a selectable DsRed marker gene under the 3xP3 eye-specific promoter (Fig. 1B).Germ-line transformation experiments were performed using a technique developed previously (Kokoza et al., 2001a).

Of 800 embryos injected with the $\mathrm{Vg}$-Gal4 driver construct, 129 survived to adulthood and gave progeny (Table $\mathrm{S} 3$ ). The $\mathrm{G}_{0}$ mosquitoes were outcrossed with the host wild-type UGAL/Rockefeller strain, and $\mathrm{G}_{1}$ progeny (larvae and pupae) were examined for EGFP in their eyes (Fig. S1A). Of 1300 embryos injected with the UAS-EGFP responder construct, 240 mosquitoes became adult. Transformants for the UAS-EGFP responder were selected for the presence of DsRed marker in their eyes (Fig. S1B). Two independent $V g$-Gal4 driver and four $U A S$-EGFP responder transgenic lines were initially selected for further analyses (Table S2). Transformation efficiency was approximately $1.5 \%$ in both experiments.

For further analyses, we selected two lines based on a strong expression of eye-specific marker genes; one for the $V g$-Gal4 driver (DA55) and another for the UAS-EGFP responder (R-234). Both these lines were established as homozygous for respective transgenes. We considered these lines to be homozygous based on several criteria. After four generations of selection, $100 \%$ of mosquitoes in each line exhibited the eye-specific markers. In outcross experiments, individual transgenic males were crossed with wild-type females; and transgenic females to wild-type males in reciprocal crosses. All progeny, originated from individual parents, had eye-specific markers; EGFP for the $V g$ - $G A L 4$ driver and DsRed for the $U A S$-EGFP responder. Our molecular analysis using inverse PCR suggested that each line had a single copy insertion of the piggyBac transposon (Table S3). For both the DA55 driver line and the R-234 responder line, all sequenced plasmids had the same target sites of their respective transgenes confirming the unique single copy incorporation. Incorporation of respective transgenes into both DA55 driver and R-234 responder lines occurred via a bona fide, canonical, duplicated TTAA target site characteristic of the piggyBac-mediated insertion (Table S3).

Genomic PCR analysis was conducted to confirm a stable incorporation and the integrity of $V g$-Gal4 and UAS-EGFP constructs into the Ae. aegypti genome in the DA-55 driver and the R-234 responder lines. For each line, the genomic DNA was isolated from 7-10 transgenic mosquitoes, and aliquots of these samples were analyzed by PCR using a pair of primers specific for piggyBac transposon left arm, right arm, $V g$-Gal4 driver and UAS-EGFP responder sequences (Fig. 2). The integrity of isolated genomic DNA was confirmed by PCR amplification of the endogenous actin gene as a positive control. The DNA isolated from wild-type (UGAL) mosquitoes was used as a negative control (Fig. 2). The transgenespecific primer sets confirmed the presence of piggyBac transposon sequences (left arm and right arm) in genomic DNA isolated from mosquitoes of DA55 and R-234 lines (Fig. 2A 
and 2B). $V g$-Gal4 driver sequence was present in genomic DNA isolated from of the DA55 line, while the UAS-EGFP responder sequence was present in DNA from the R-234 line. No amplification was observed in genomic DNA isolated from the non-transgenic parental UGAL strain (Fig. 2D).

After stable $V g$-Gal4 driver and UAS-EGFP responder homozygous lines had been established, we produced $V g$-Gal4/UAS-EGFP hybrid mosquitoes by crossing these two transgenic lines and selecting mosquitoes with the simultaneous presence of both EGFP and DsRed eye-specific markers (Figs. S1C, D). Genomic PCR analysis confirmed the presence of piggyBac transposon sequences (left arm and right arm) in genomic DNA isolated from $V g$-Gal4/UAS-EGFP hybrid mosquitoes. Moreover, both Vg-Gal4 and UAS-EGFP sequences were present in genomic DNA from the hybrid mosquitoes (Fig. 2). There were no detectable negative effects on mosquito development, egg production, viability or sex ratio in either of these two transgenic lines, or in the $V g$-Gal4/UAS-EGFP hybrid mosquitoes (data not shown).

\subsection{Expression Analysis}

To demonstrate whether the constructed Gal4/UAS system worked in Ae. aegypti mosquitoes, we carried out a detailed expression analysis. The RT-PCR analysis was performed using a pair of primers that recognized the transgenic $\mathrm{Vg}$-Gal4 hybrid transcripts specifically and not the endogenous $V g$ mRNA (Kokoza et al., 2000; 2001a). The parental UGAL strain was used as a negative control of expression in all experiments. No $\mathrm{Vg}$-Gal4 transcript was observed at the previtellogenic stage of any transgenic line. The $\mathrm{Vg}$-Gal4 transcript was found in the fat body of the transgenic female mosquitoes of the DA-55 driver line after a blood meal, when it reached a peak at $24 \mathrm{~h} \mathrm{PBM}$ in accordance with the expression of the $V g$ promoter driver. The $V g$-Gal4 transcript had a similar pattern in the $V g$ Gal4/UAS-EGFP hybrids (Figs. 3A, B). No expression of the transgenic $\mathrm{Vg}$-Gal4 activator transcript was observed in the responder UAS-EGFP line or the parental UGAL mosquitoes (Figs. 3C, D). These results clearly demonstrate that the transgenic $V g$-Gal4 activator is transcribed PBM in both the DA55 driver line and the Vg-Gal4/UAS-EGFP hybrid mosquitoes.

The RT-PCR analysis using EGFP-specific primers showed that this transcript was found only in the hybrid $V g$-Gal4/UAS-EGFP transgenic mosquitoes (Fig. 3A). EGFP mRNA expression was detected in neither the DA-55 driver nor the R-234 responder lines (Figs. 3B and C). No EGFP mRNA was seen in the UGAL parental mosquitoes (Fig. 3D). The EGFP transcript was found only in the fat body, not in the ovary, midgut, or Malpighian tubules of the $V g$-Gal4/UAS-EGFP female mosquitoes (Fig. 4). Males of the same hybrid line were negative for the EGFP transcript (Fig. 4). These data indicate that transactivation of the reporter gene in the established Gal4/UAS binary system occur in a tissue-, sex-, and stagespecific manner and resemble the expression of the endogenous $V g$ gene (Figs. 3 and 4).

Microscopic fluorescence analysis was used to establish that the reporter mRNA was not only transcribed but also was efficiently translated in the $V g$-Gal4/UAS-EGFP female mosquitoes. Strong EGFP fluorescence was observed in abdomens of these mosquitoes after blood feeding; it reached a maximum at $24 \mathrm{~h}$ PBM and persisted until $48 \mathrm{~h} \mathrm{PBM} \mathrm{(Fig.} \mathrm{5).}$ No positive signal was observed in females of the driver DA-55 driver, the R-234 responder lines or UGAL mosquitoes (Fig. 5).

\subsection{In vitro activation of the $\mathrm{Vg}$-Gal4/UAS expression system in the fat body by $20 \mathrm{E}$}

$20 \mathrm{E}$ is the major regulator of mosquito vitellogenesis (Raikhel et al., 2005). We conducted in vitro tissue culture experiments to determine whether 20E activates $V g$-Gal4/UAS-EGFP 
in the fat bodies of transgenic mosquitoes (Raikhel et al., 1997; Roy et al., 2007). Fat bodies isolated from previtellogenic $V g$-Gal4/UAS-EGFP hybrid female mosquitoes were incubated for $6 \mathrm{~h}$ in culture medium in the presence or absence of 20E. We performed RTPCR analysis utilizing gene-specific primers to UAS-EGFP reporter, $V g$-Gal4 and actin as a loading control. This analysis revealed the presence of high levels of both UAS-EGFP and $V g$-Gal4 transcripts in fat bodies from previtellogenic $V g$-Gal4/UAS-EGFP female mosquitoes treated with 20E (Fig. 6). Thus, the $V g$-Gal4/UAS-EGFP system was activated by the hormone treatment at the transcriptional level.

To determine whether 20E-activated expression of the $V g$-Gal4/UAS-EGFP resulted in translation of EGFP, we conducted fluorescence microscopy analysis of the fat bodies isolated from the previtellogenic $V g$-Gal4/UAS-EGFP females after in vitro hormonal treatment with 20E, as described above. This visual analysis revealed a high level of GFP fluorescence in the fat body tissue (Figs. 7A, B, C; Fig. 8A). No EGFP fluorescence was observed in fat bodies from the DA-55 driver, R-234 responder or parental UGAL mosquitoes (Figs. 8B, C, D).

\section{Discussion}

We have reported here the establishment of the binary Gal4/UAS system for the yellow fever mosquito Ae. aegypti. The results show that the $V g$-Gal4 driver leads to a high level of tissue-, stage- and sex-specific expression of the EGFP reporter in the fat body of $\mathrm{Vg}$-Gal4/ $U A S-E G F P$ mosquitoes after blood-meal activation. We utilized the 1.8-kb 5' upstream regulatory region of the $V g$ gene, which has been shown be sufficient to lead expression of a transgene in manner similar to that of the endogenous $V g$ gene (Kokoza et al., 2000; 2001a; $2001 b)$. Activation of the $V g$ gene was shown to depend on ingestion of blood by female mosquitoes, and it was expressed in a strict sex-specific, tissue-specific and temporal manner. The level of its expression increased dramatically by $24 \mathrm{~h}$ PBM and then declined to a background level by 36-42 h PBM. The $V g$ gene was expressed exclusively in the female fat body, which is the tissue central to reproduction, immunity and metabolism. The $V g$ promoter provides an ideal driver for expression of genes of interest in this important tissue, as it has been demonstrated in previous studies (Antonova et al., 2009; Bian et al., 2005; Shin et al., 2003; Shin et al. 2006; Cheon et al., 2006; Kokoza et al., 2010). The EGFP transcript was present only in fat bodies of female mosquitoes after a blood meal, with its maximal level at $24 \mathrm{~h}$ PBM. Moreover, the EGFP protein was translated, as judged by EGFP fluorescence in the abdomens of $V g$-Gal4/UAS-EGFP. Due to stability of EGFP, the fluorescent signal was observed in female mosquitoes even at $48 \mathrm{~h}$ PBM. A similar prolonged presence of an expressed product had been reported previously for Defensin in the transgenic Ae. aegypti (Kokoza et al., 2000). Thus, our $V g$-Gal4/UAS-EGFP system is ready for expression of target genes, their modifications, or target gene depletions. The development of the mosquito GaL4/UAS system will clearly lead to: 1) identification and in vivo testing of robust stage- and tissue-specific promoters; and 2) characterization of genes critical for reproduction or survival of a mosquito.

Initiation and maintenance of the $V g$ gene expression is accomplished by the cooperative action of the nutritional amino acid/Target of Rapamycin signaling and 20E pathways (Attardo et al., 2005; Raikhel et al., 2005). The 20E regulatory hierarchy controls $V g$ gene expression via transcription factors: the ecdysone receptor (EcR/USP), E74 and Broad (Raikhel et al., 2002; 2005). cis binding sites complementary to these transcription factors are present in the 1.8-kb $V g$ 5' upstream region used for creating the $V g$-GAL4 driver. In vitro organ culture experiments utilizing fat bodies from previtellogenic $\mathrm{Vg}$-Gal4/UAS$E G F P$ females have shown that $V g$-Gal4 is responsive to the physiological dose of $20 \mathrm{E}$ in the presence of amino acids and activated the EGFP gene via GAL4-UAS interaction. 
EGFP protein was translated, resulting in an intense fluorescence of the incubated fat bodies. Hence, our data expand the applicability of the established $V g$-Gal4/UAS system not only for an in vivo analysis, but also for in vitro tissue culture studies of gene expression regulation.

Transformation efficiencies via transposable elements for non-Drosophilid insects are low. In this work, it was $1.5 \%$ in both transformation vectors. This is in a range of efficiency typical for mosquito species (Kokoza et al., 2001a, Kim et. al., 2004; Lobo et al., 2002; Labbe et al., 2010). Similar transformation efficiencies have been observed in other insects, such as 2.5-2.7\% in Bombyx mori (Imamura et al., 2003), 3-5\% in the Mediterranean fruit fly (Handler et al., 1998) and 4-5\% in Tribolium castaneum (Victorinova et al., 2007). Recently, a tenfold increase in transformation efficiency has been reported using a newly developed hyperactive version of the piggyBac transposase (Yusa et al., 2010). Further advancements in genetic transformation tools are required to increase effectiveness of the GAL4/UAS system in non-Drosophilid insects.

Further expansion of research utilizing the binary Gal4/UAS system in mosquitoes to investigate their unique biology depends largely on characterization of tissue-, cell-, sexand stage-specific genes, regulatory regions of which could be utilized as drivers for the binary mosquito Gal4/UAS system. A number of mosquito genes have been characterized and utilized in generating transgenic mosquitoes-Ae. aegypti, An. stephensi and An. gambiae (Kokoza et al., 2000, Ito et al., 2000, Cho et al., 2006; Adelman et al., 2007; Papathanos et al., 2009; Catteruccia et al., 2005; Smith et al., 2007; Nolan et al., 2011). However, further detailed studies are required to match the sophistication of genetic approaches utilizing the binary GAL4/UAS system in model organisms. Our study represents a significant step in the development of genetic tools in mosquitoes.

\section{Supplementary Material}

Refer to Web version on PubMed Central for supplementary material.

\section{Acknowledgments}

This project was supported by grants from the National Institutes of Health (R37 AI244716 and RO1 AI59492). The funders had no role in study design, data collection and analysis, decision to publish, or preparation of the manuscript.

\section{References}

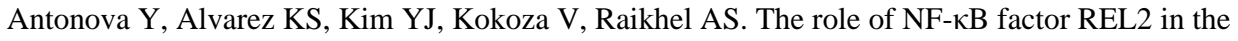
Aedes aegypti immune response. Insect Biochem. Mol. Biol. 2009; 39:303-314. [PubMed: 19552893]

Arensburger P, Megy K, Waterhouse RM, Abrudan J, Amedeo P, Antelo B, Bartholomay L, Bidwell S, Caler E, Camara F, Campbell CL, Campbell KS, Casola C, Castro MT, Chandramouliswaran I, Chapman SB, Christley S, Costas J, Eisenstadt E, Feschotte C, Fraser-Liggett C, Guigo R, Haas B, Hammond M, Hansson BS, Hemingway J, Hill SR, Howarth C, Ignell R, Kennedy RC, Kodira CD, Lobo NF, Mao C, Mayhew G, Michel K, Mori A, Liu N, Naveira H, Nene V, Nguyen N, Pearson MD, Pritham EJ, Puiu D, Qi Y, Ranson H, Ribeiro JM, Roberston HM, Severson DW, Shumway M, Stanke M, Strausberg RL, Sun C, Sutton G, Tu ZJ, Tubio JM, Unger MF, Vanlandingham DL, Vilella AJ, White O, White JR, Wondji CS, Wortman J, Zdobnov EM, Birren B, Christensen BM, Collins FH, Cornel A, Dimopoulos G, Hannick LI, Higgs S, Lanzaro GC, Lawson D, Lee NH, Muskavitch MA, Raikhel AS, Atkinson PW. Sequencing of Culex quinquefasciatus establishes a platform for mosquito comparative genomics. Science. 2010; 330:86-88. [PubMed: 20929810]

Arnosti DN, Gray S, Barolo S, Zhou J, Levine M. The gap protein knirps mediates both quenching and direct repression in the Drosophila embryo. EMBO J. 1996; 15:3659-3666. [PubMed: 8670869] 
Attardo GM, Hansen IA, Raikhel AS. Nutritional regulation of vitellogenesis in mosquitoes: Implications for anautogeny. Insect Biochem. Mol. Biol. 2005; 35:661-675. [PubMed: 15894184]

Baier H, Scott EK. Genetic and optical targeting of neural circuits and behavior zebrafish in the spotlight. Curr. Opin. Neurobiol. 2009; 19:553-560. [PubMed: 19781935]

Bian G, Shin SW, Cheon HM, Kokoza V, Raikhel AS. Transgenic alteration of Toll immune pathway in the female mosquito Aedes aegypti. Proc. Natl. Acad. Sci. USA. 2005; 102:13568-13573. [PubMed: 16157887]

Blandin S, Motia KF, Kocher T, Wilm M, Kafatos FC, Levashina EA. Reverse genetics in the mosquito Anopheles gambiae: targeted disruption of the defensin gene. EMBO Rep. 2002; 3:852856. [PubMed: 12189180]

Bonizzoni M, Dunn WA, Campbell CL, Olson KE, Dimon MT, Marinotti O, James AA. RNA-seq analyses of blood-induced changes in gene expression in the mosquito vector species, Aedes aegypti. BMC Genomics. 2011; 12:82. [PubMed: 21276245]

Brand AH, Perrimon N. Targeted gene expression as a means of altering cell fates and generating dominant phenotypes. Development. 1993; 118:401-415. [PubMed: 8223268]

Cateruccia F, Benton JP, Crisanti A. An Anopheles transgenic sexing strain for vector control. Nat. Biotechnol. 2005; 23:1414-1417. [PubMed: 16244659]

Catteruccia F, Nolan T, Loukeris TG, Blass C, Savakos C, Kafatos FC, Crisanti A. Stable germline transformation of the malaria mosquito Anopheles stephensi. Nature. 2000; 405:959-962. [PubMed: 10879538]

Cheon H-M, Shin SW, Bian G, Park JH, Raikhel AS. Regulation of lipid metabolism genes, lipid carrier protein lipophorin and its receptor, during immune challenge in the mosquito Aedes aegypti. J. Biol. Chem. 2006; 281:8426-8435. [PubMed: 16449228]

Cho KH, Cheon H-M, Kokoza V, Raikhel AS. Regulatory region of the vitellogenin receptor gene sufficient for high level, germ line cell-specific expression in the ovary of transgenic Aedes aegypti mosquitoes. Insect Biochem. Mol. Biol. 2006; 36:273-281. [PubMed: 16551541]

Coates CJ, Jasinskiene N, Miyashiro L, James AA. Mariner transposition and transformation of the yellow fever mosquito, Aedes aegypti. Proc. Natl Acad. Sci. USA. 1998; 95:3748-3751. [PubMed: 9520438]

Corby-Harris V, Drexler A, Watkins de Jong L, Antonova Y, Pakpour N, Ziegler R, Ramberg F, Lewis EE, Brown JM, Luckhart S, Riehle MA. Activation of Akt signaling reduces the prevalence and intensity of malaria parasite infection and lifespan in Anopheles stephensi mosquitoes. PloS Pathogens. 2011; 6(7) e1001003.

Dimopoulos G, G. K. Christophides S, Meister J, Schultz KP, Schultz J, White KP, Barillas-Mury C, Kafatos FC. Genome expression analysis of Anopheles gambiae: responses to injury, bacterial challenge, and malaria infection. Proc. Natl. Acad. Sci. USA. 2002; 99:8814-8819. [PubMed: 12077297]

Duffy JB. GAL4 system in Drosophila: a fly geneticist's Swiss army knife. Genesis. 2002; 34:1-15. [PubMed: 12324939]

Franz AW, Sanchez-Vargas I, Adelman ZN, Blair CD, Beaty BJ, James AA, Olson KE. Engineering RNA interference-based resistance to dengue virus type 2 in genetically modified Aedes aegypti. Proc. Natl. Acad.Sci. USA. 2006; 103:4198-4203. [PubMed: 16537508]

Fu G, Lees RS, Nimmo D, Aw D, Jin L, Gray P, Berendonk TU, White-Cooper H, Scife S, Phuc HK, Mariotti O, Jasinskiene N, James AA, Alphey L. Female-specific flightless phenotype for mosquito control. Proc. Natl. Acad.Sci. USA. 2010; 107:4550-4554. [PubMed: 20176967]

Guyer D, Tuttle A, Rouse S, Volrath S, Johnson M, Potter S, Gorlach J, Goff S, Crossland L, Ward E. Activation of latent transgenes in Arabidopsis using a hybrid transcription factor. Genetics. 1998; 149:633-639. [PubMed: 9611179]

Handler AM, McCombs SD, Fraser MJ, Saul SH. The lepidopteran transposon vector, piggyBac, mediates germ-line transformation in the Mediterranean fruit fly. Proc. Natl. Acad. Sci. USA. 1998; 95:7520-7525. [PubMed: 9636182]

Handler AM, Harrell RA II. Germline transformation of Drosophila melanogaster with the piggyBac transposon vector. Insect Mol. Biol. 1999; 8:449-457. [PubMed: 10634970] 
Hartley KO, Nutt SL, Amaya E. Targeted gene expression in transgenic Xenopus using the binary Gal4/UAS system. Proc. Natl. Acad. Sci. USA. 2002; 99:1377-1382. [PubMed: 11818539]

Holt RA, Subramanian GM, Halpern A, Sutton GG, Charlab R, Nusskern DR, Wincker P, Clark AG, Ribeiro JM, Wides R, Salzberg SL, Loftus B, Yandell M, Majoros WH, Rusch DB, Lai Z, Kraft CL, Abril JF, Anthouard V, Arensburger P, Atkinson PW, Baden H, de Berardinis V, Baldwin D, Benes V, Biedler J, Blass C, Bolanos R, Boscus D, Barnstead M, Cai S, Center A, Chaturverdi K, Christophides GK, Chrystal MA, Clamp M, Cravchik A, Curwen V, Dana A, Delcher A, Dew I, Evans CA, Flanigan M, Grundschober-Freimoser A, Friedli L, Gu Z, Guan P, Guigo R, Hillenmeyer ME, Hladun SL, Hogan JR, Hong YS, Hoover J, Jaillon O, Ke Z, Kodira C, Kokoza E, Koutsos A, Letunic I, Levitsky A, Liang Y, Lin JJ, Lobo NF, Lopez JR, Malek JA, McIntosh TC, Meister S, Miller J, Mobarry C, Mongin E, Murphy SD, O'Brochta DA, Pfannkoch C, Qi R, Regier MA, Remington K, Shao H, Sharakhova MV, Sitter CD, Shetty J, Smith TJ, Strong R, Sun J, Thomasova D, Ton LQ, Topalis P, Tu Z, Unger MF, Walenz B, Wang A, Wang J, Wang M, Wang X, Woodford KJ, Wortman JR, Wu M, Yao A, Zdobnov EM, Zhang H, Zhao Q, Zhao S, Zhu SC, Zhimulev I, Coluzzi M, della Torre A, Roth CW, Louis C, Kalush F, Mural RJ, Myers EW, Adams MD, Smith HO, Broder S, Gardner MJ, Fraser CM, Birney E, Bork P, Brey PT, Venter JC, Weissenbach J, Kafatos FC, Collins FH, Hoffman SL. The genome sequence of the malaria mosquito Anopheles gambiae. Science. 2002; 298:129-149. [PubMed: 12364791]

Horn C, Wimmer EA. A versatile vector set for animal transgenesis. Dev. Genes Evol. 2000; 210:630637. [PubMed: 11151300]

Imamura M, Nakai J, Inoue S, Quan GX, Kanda T, Tamura T. Targeted gene expression using the GAL4/UAS system in the silkworm Bombyx mori. Genetics. 2003; 165:1329-1340. [PubMed: 14668386]

Ito J, Ghosh A, Moreira LA, Wimmer EA, Jacobs-Lorena M. Transgenic anopheline mosquitoes impaired in transmission of a malaria parasite. Nature. 2002; 417:452-455. [PubMed: 12024215]

James AA. Gene drive systems in mosquitoes: rules of the road. Trends Parasitol. 2005; 21:64-67. [PubMed: 15664528]

Jasinskiene N, Coates CJ, Benedict MQ, Cornel AJ, Salazar-Rafferty C, James AA, Collins FH. Stable, transposon-mediated transformation of yellow fever mosquito, Aedes aegypti, using Hermes element from the housefly. Proc. Natl. Acad. Sci. USA. 1998; 95:3743-3747. [PubMed: 9520437]

Kim W, Koo H, Richman AM, Seeley D, Vizioli J, Klocko AD, O'Brochta DA. Ectopic expression of a cecropin transgene in the human malaria vector mosquito Anopheles gambiae (Diptera: Culicidae): effect on susceptibility to Plasmodium. J.Med. Entomol. 2004; 41:447-455. [PubMed: 15185949]

Kokoza V, Ahmed A, Cho W-L, Jasinkiene N, James AA, Raikhel AS. Engineering blood mealactivated systemic immunity in the yellow fever mosquito, Aedes aegypti. Proc. Natl. Acad. Sci. USA. 2000; 97:9144-9149. [PubMed: 10908672]

Kokoza V, Ahmed A, Wimmer EA, Raikhel AS. Efficient transformation of the yellow fever mosquito Aedes aegypti using the piggyBac transposable element vector $\mathrm{pBac}[3 \mathrm{xP} 3-\mathrm{EGFP} \mathrm{afm}$. Insect Biochem. Mol. Biol. 2001a; 31:1137-1143. [PubMed: 11583926]

Kokoza V, Ahmed A, Shin SW, Okafor N, Zou Z, Raikhel AS. Blocking of Plasmodium transmission by cooperative action of Cecropin A and Defensin A in transgenic Aedes aegypti mosquitoes. Proc Natl Acad Sci USA. 2010; 107:8111-8116. [PubMed: 20385844]

Kokoza VA, Martin D, Mienaltowski MJ, Ahmed A, Morton CM, Raikhel AS. Transcriptional regulation of the mosquito vitellogenin gene via a blood meal-triggered cascade. Gene. 2001b; 274:47-65. [PubMed: 11674997]

Kulkarni M, Arnosti DN. Information display by transcriptional enchancers. Development. 2003; 130:6569-6575. [PubMed: 14660545]

Labbé GM, Nimmo DD, Alphey L. piggyBac- and PhiC31-mediated genetic transformation of the asian tiger mosquito, Aedes albopictus (Skuse). PLoS Negl. Trop.Dis. 2010; 4(8):e788. [PubMed: 20808959]

Lobo NF, Hua-Van A, Li X, Nolen BM, Fraser MJ Jr. Germ line transformation of the yellow fever mosquito, Aedes aegypti, mediated by transpositional insertion of a piggyBac vector. Insect Mol. Biol. 2002; 11:133-139. [PubMed: 11966878] 
Mallo M. Controlled activation and inactivation in the mouse. Front Biosci. 2006; 1:313-327. [PubMed: 16146733]

Mathur G, Sanchez-Vargas I, Alvarez D, Olson KE, Marinotti O, James AA. Transgene-mediated suppression of dengue viruses in the salivary glands of the yellow fever mosquito, Aedes aegypti. Insect Mol. Biol. 2010; 19:753-763. [PubMed: 20738425]

McGuire SE, Mao Z, Davis RL. Spatiotemporal gene expression targeting with the TARGET and gene-switch systems in Drosophila. Sci STKE. 2004; 2004:pI6.

Neira-Oviedo M, Tsyganov-Bodounov A, Lycett GJ, Kokoza V, Raikhel AS, Krzywinski J. The RNASeq approach to studying the expression of mosquito mitochondrial genes. Insect Mol Biol. 2011; 20:141-152. [PubMed: 20958808]

Nene V, Wortman JR, Lawson D, Haas B, Kodira C, Tu ZJ, Loftus B, Xi Z, Megy K, Grabherr M, Ren Q, Zdobnov EM, Lobo NF, Campbell KS, Brown SE, Bonaldo MF, Zhu J, Sinkins SP, Hogenkamp DG, Amedeo P, Arensburger P, Atkinson PW, Bidwell S, Biedler J, Birney E, Bruggner RV, Costas J, Coy MR, Crabtree J, Crawford M, Debruyn B, Decaprio D, Eiglmeier K, Eisenstadt E, El-Dorry H, Gelbart WM, Gomes SL, Hammond M, Hannick LI, Hogan JR, Holmes MH, Jaffe D, Johnston JS, Kennedy RC, Koo H, Kravitz S, Kriventseva EV, Kulp D, Labutti K, Lee E, Li S, Lovin DD, Mao C, Mauceli E, Menck CF, Miller JR, Montgomery P, Mori A, Nascimento AL, Naveira HF, Nusbaum C, O'leary S, Orvis J, Pertea M, Quesneville H, Reidenbach KR, Rogers YH, Roth CW, Schneider JR, Schatz M, Shumway M, Stanke M, Stinson EO, Tubio JM, Vanzee JP, Verjovski-Almeida S, Werner D, White O, Wyder S, Zeng Q, Zhao Q, Zhao Y, Hill CA, Raikhel AS, Soares MB, Knudson DL, Lee NH, Galagan J, Salzberg SL, Paulsen IT, Dimopoulos G, Collins FH, Birren B, Fraser-Liggett CM, Severson DW. Genome sequence of Aedes aegypti a major arbovirus vector. Science. 2007; 316:1718-1723. [PubMed: 17510324]

Nimmo DD, Alphey LS, Meredith JM, Eggleston P. High efficiency sites-specific genetic engineering of the mosquito genome. Insect Mol. Biol. 2006; 15:129-136. [PubMed: 16640723]

Nolan T, Petris E, Muller HM, Cronin A, Cateruccia F, Crisanti A. Analysis of two novel midgutspecific promoters driving transgene expression in Anopheles stephensi mosquitoes. PLoS One. 2011; 6(2):e16471. [PubMed: 21326609]

Ornitz DM, Moreadith RW, Leder P. Binary system for regulating transgene expression in mice: targeting int-2 gene expression with yeast GAL4/UAS control elements. Proc. Natl. Acad. Sci. USA. 1991; 88:698-702. [PubMed: 1846961]

Papathanos PA, Windbichler N, Menichelli M, Burt A, Crisanti A. The vasa regulatory region mediates germline expression and maternal transmission of proteins in the malaria mosquito Anopheles gambiae: a versatile tool for genetic control strategy. BMC Mol. Biol. 2009; 10:65. [PubMed: 19573226]

Raikhel, AS.; Brown, M.; Belles, X. Endocrine control of reproductive processes. In: Gilbert, L.; Gill, S.; Iatrou, K., editors. Comprehensive Molecular Insect Science. Amsterdam: Elsevier; 2005. p. 433-491.

Raikhel, AS.; Deitsch, KW.; Sappington, TW. Culture and analysis of the insect fat body. In: Crampton, JM.; Beard, CB.; Louis, C., editors. The molecular biology of insect disease vectors. A methods manual. London: Chapman and Hall; 1997. p. 507-522.

Raikhel AS, Kokoza VA, Zhu J, Martin D, Wang SF, Li C, Sun G, Ahmed A, Dittmer N, Attardo G. Molecular biology of mosquito vitellogenesis: from basic studies to genetic engineering of antipathogen immunity. Insect Biochem. Mol. Biol. 2002; 32:1275-1286. [PubMed: 12225918]

Roy SG, Hansen IA, Raikhel AS. Effect of insulin and 20-hydroxyecdysone in the fat body of the yellow fever mosquito, Aedes aegypti. Insect Biochem. Mol. Biol. 2007; 37:1317-1326. [PubMed: 17967350]

Scheer N, Campos-Ortega JA. Use of the Gal4-UAS technique for targeted gene expression in the zebrafish. Mech. Dev. 1999; 80:153-158. [PubMed: 10072782]

Schinko JB, Weber M, Viktorinova I, Kiupakis A, Averof M, Klinger M, Wimmer EA, Bucher G. Functionality of the GAL4/UAS system in Tribolium requires the use of endogenous core promoters. BMC Developmental Biology. 2010; 10:53. [PubMed: 20482875]

Shin SW, Kokoza V, Lobkov I, Raikhel AS. Relish-mediated immune deficiency in the transgenic mosquito Aedes aegypti. Proc. Natl. Acad. Sci. USA. 2003; 100:2616-2621. [PubMed: 12594340] 
Shin SW, Bian G, Raikhel AS. A toll receptor and a cytokine, Toll5A and Spz1C, are involved in toll antifungal immune signaling in the mosquito Aedes aegypti. J. Biol. Chem. 2006; 281:3938839395. [PubMed: 17068331]

Smith RC, Walter MF, Hice RH, O'Brochta DA, Atkinson PW. Testis-specific expression of the beta2 tubulin promoter of Aedes aegypti and its application as a genetic sex-separation marker. Insect Mol. Biol. 2007; 16:61-71. [PubMed: 17257209]

Terenius O, Marinotti O, Sieglaff D, James AA. Molecular genetic manipulation of vector mosquitoes. Cell Host. Microbe. 2008; 4:417-423. [PubMed: 18996342]

Viktorinova I, Wimmer EA. Comparative analysis of binary expression systems for directed gene expression in transgenic insects. Insect Biochem. Mol. Biol. 2007; 37:246-254. [PubMed: 17296499]

Yusa K, Zhou L, Li MA, Bradley A, Craig NL. A hyperactive piggyBac transposase for mammalian applications. Proc. Natl. Acad. Sci. USA. 2011; 108:1531-1536. [PubMed: 21205896] 


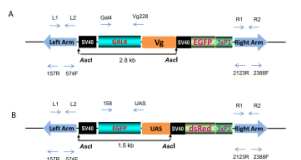

Fig. 1.

Schematic representation of two constructs, the pBac[3xP3-EGFP afm, Vg-Gal4] - driver (A) and the pBac[3xp3-DsRed af, $U A S-E G F P]$ - responder (B) used in germ-line transformation experiments. The $2.8-\mathrm{kb}$ driver transgene consists of the Ae. aegypti mosquito's $V g$ - 5' promoter region linked to yeast Gal4 activator sequence with DNA binding domain (amino acids, 1-93) and activation domain (amino acids, 753-881), followed by SV40 polyA signal (A). The $1.5-\mathrm{kb}$ responder transgene contains the UAS sequence with $5 \times$ concatamers of the Gal4 binding sites fused to the EGFP reporter gene with SV40 polyA signal (B). The transgene-specific primers used for genomic PCR, RTPCR and inverse PCR are indicated by the arrows above and below the diagram. 


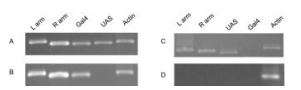

Fig. 2.

Stable incorporation and integrity of the $V g$-Gal4 driver and $U A S$-EGFP responder transposons into the Ae. aegypti genome. Genomic DNA was isolated from transgenic mosquitoes of the $V g$-Gal4/UAS-EGFP hybrids (A), the driver line (B), the responder line (C), and non-transgenic UGAL strain (D). PCR amplification was performed using a set of primers specific to the left and right arms of the piggyBac vector ( $\mathrm{L}$ arm and $\mathrm{R}$ arm), the $V g$ Gal4 transgene (Gal4) and the UAS-EGFP transgene (UAS). Primers to Ae. aegypti actin were used to confirm the integrity of genomic DNA. 
A

Vg-Gal4

Actin
Vg-Gal4/UAS-EGFP

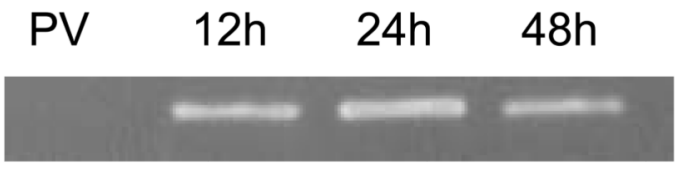

Vitellogenin

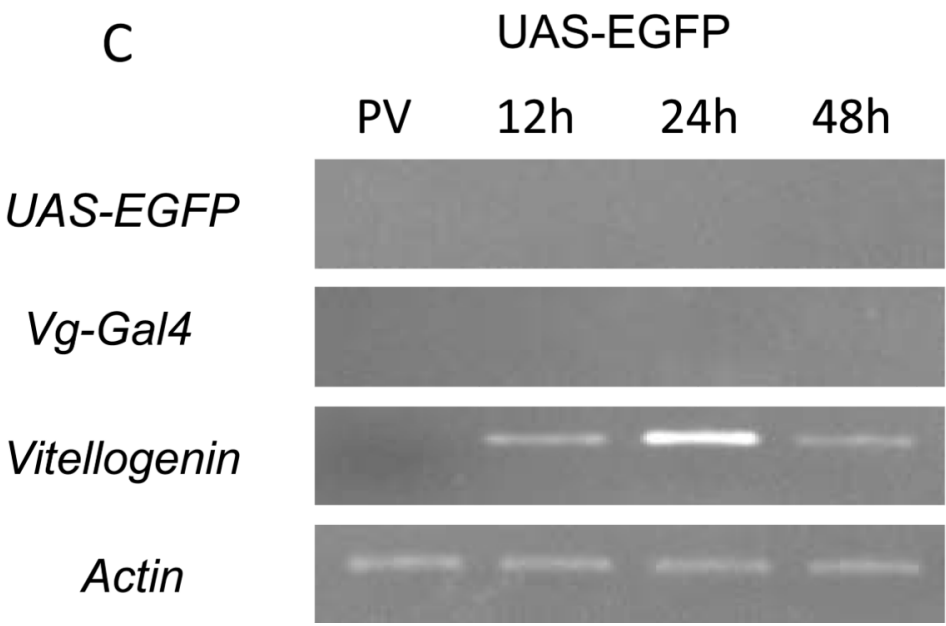

B
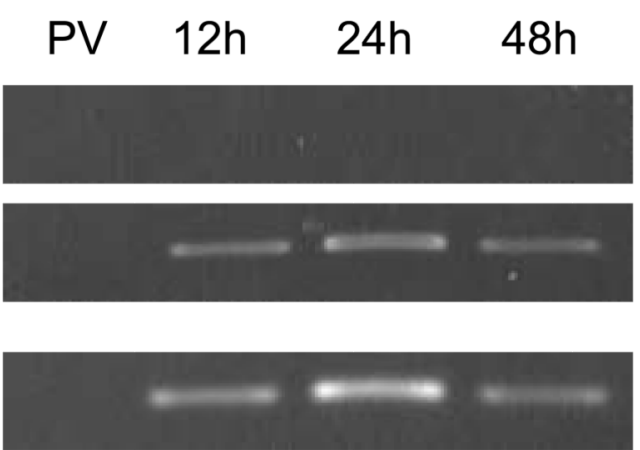

D UGAL
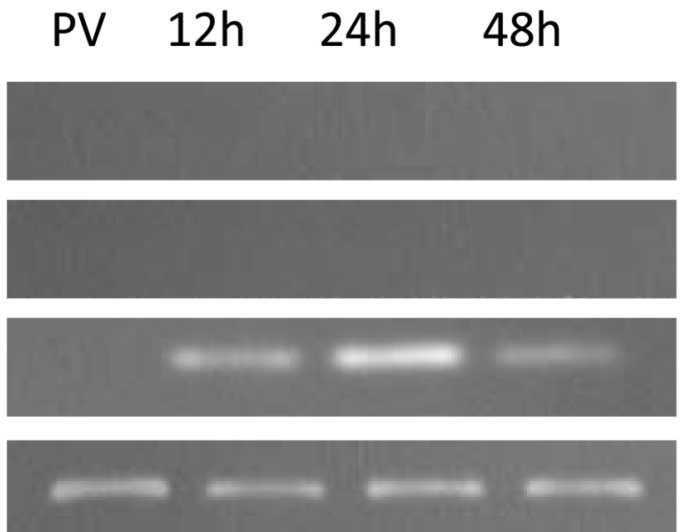

Fig. 3.

Blood meal activation of the binary $V g$-Gal4/UAS-EGFP expression system in the fat body of the transgenic Ae. aegypti mosquitoes. RT-PCR analysis was performed using RNA samples isolated from the fat body of transgenic (A, B, C) and wild-type UGAL (D) mosquitoes. Expression profiles of the $V g$-Gal4, UAS-EGFP transgenes, vitellogenin and actin in previtellogenic (PV) and vitellogenic females were analyzed 12, 24, and $48 \mathrm{~h}$ postblood meal (PBM) using gene-specific primers. 
Fig. 4.

Tissue- and sex-specific expression of the reporter gene in the $V g$-Gal4/UAS-EGFP hybrid mosquitoes. Fat bodies (FB), ovaries (OV), midgut (MG), and Malpighian tubules (MT) from vitellogenic $V g$-Gal4/UAS-EGFP hybrid female mosquitoes, 24 h post-blood meal (PBM), were analyzed by means of RT-PCR analysis. Specific amplification of the EGFP reporter was detected only in vitellogenic fat bodies. Males $(\mathrm{M})$ were also negative for EGFP reporter RNA. Actin-specific primers were used as a control for RNA integrity and loading. 


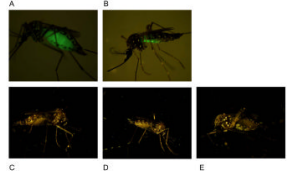

Fig. 5.

Tissue- and stage-specific EGFP reporter expression in the $V g$-Gal4/UAS-EGFP hybrid female mosquitoes after blood meal activation. Fluorescent images of adult vitellogenic females were captured using an EGFP filter set. Expression of EGFP reporter was detected only in the fat body of hybrid Vg-Gal4/UAS-EGFP females 24 (A) and 48 (B) h post-blood meal (PBM). No EGFP fluorescence was observed in the fat body of vitellogenic ( $24 \mathrm{~h}$ PBM) females of the $V g$-Gal4 driver (C) and $U A S$-EGFP responder (D) transgenics, or nontransgenic UGAL strain (E). 
$20 E(-) \quad 20 E(+)$

UAS-EGFP
vg-Gal4
ACTIN

Fig. 6.

20E hormonal activation of reporter mRNA expression in the Vg-Gal4/UAS-EGFP hybrids in previtellogenic fat body in an in vitro organ culture. Previtellogenic fat bodies were incubated in culture media in the presence $(20 \mathrm{E}+)$ or absence of $(20 \mathrm{E}-)$ of $20 \mathrm{E}$. RT-PCR analysis was performed using gene-specific primers to $U A S$-EGFP reporter, $V g$ - $G a l 4$ activator and actin as a loading control. 


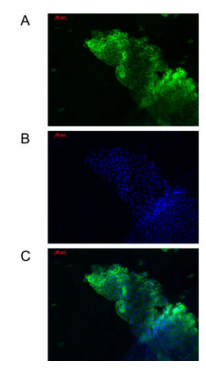

Fig. 7.

Fluorescent images of previtellogenic fat body of $\mathrm{Vg}$-Gal4/UAS-EGFP hybrids after 20E hormonal activation in an in vitro organ culture. Fat bodies dissected from previtellogenic hybrid transgenic female mosquitoes were incubated in the culture medium in the presence of $20 \mathrm{E}$ and prepared for examination by fluorescence microscopy. The tissue was stained by Hoescht DNA staining for visualization of nuclei. Imaging was performed under a Zeiss AxioObserver A1 microscope using EGFP filter (A), Blue filter for nuclei staining (B), and both filters to obtain a merged image (C). All images have a 50- $\mu \mathrm{m}$ scale. 

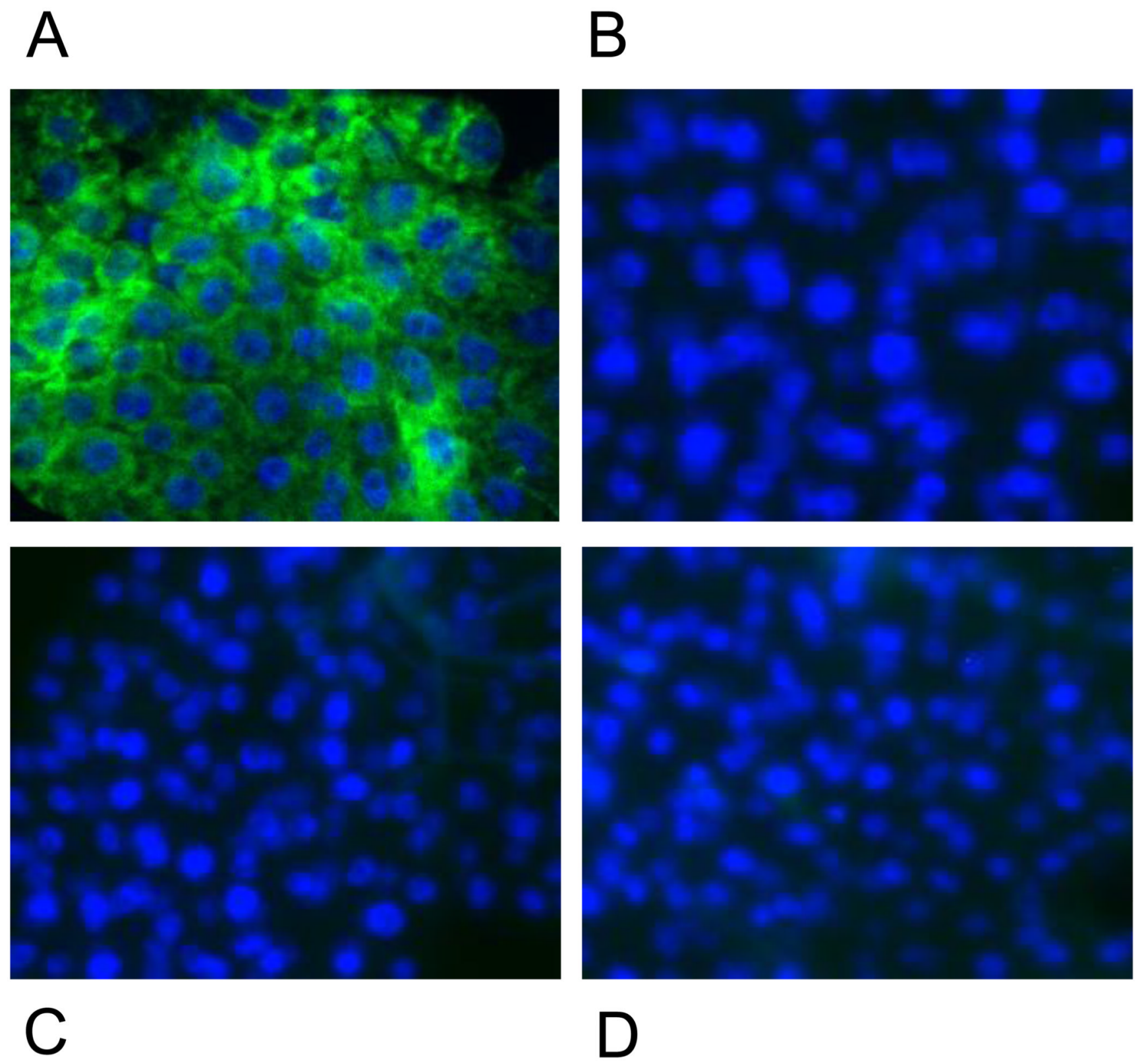

Fig. 8.

Comparison of EGFP reporter expression in fat bodies of transgenic and non-transgenic female mosquitoes after $20 \mathrm{E}$ activation in an in vitro organ culture. Specific EGFP expression was observed only in the $V g$-Gal4/UAS-EGFP hybrids (A), but not in the $V g$ Gal4 driver (B), UAS-EGFP reporter (C), or non-transgenic UGAL females (D). Imaging was performed with a Zeiss AxioObserver A1 microscope using EGFP and Blue filters to obtain merged images of fat body preparations. 